\title{
NEW ALLOYING CONCEPT FOR FINISHING MILL ROLLS INCLUDING RESULTS IN APPLICATION AND SURFACE TESTS
}

Michael Brandner '

Armin Paar '

Sander Mul ${ }^{2}$

\begin{abstract}
ESW's brand VANIMO can be considered as the latest development in Graphitic HSS roll grades for the last finishing stands in hot strip mills. These grades are based on the alloying concept of carbide enhancement of Indefinite Chill work roll materials. The amount and types of carbide forming elements are varied and adjusted according to the experience of cast HSS roll grades. The microstructure of these roll grades therefore consists of tempered martensite, cementite and several different carbide types as well as a well-defined amount of free graphite. The main goal of graphitic HSS roll grades is the combination of the high surface quality of ICDP alloys as well as the high wear resistance of HSS roll grades. Systematic steps were tested to increase the wear performance from earlier made Carbide-Enhanced ICDP grades to the more advanced VANIC grade and ended now in the highest alloyed roll grade VANIMO. In every trial, the surface quality of the roll and the strip was carefully monitored. The investment in new testing equipment at ESW's plant was decided to get more information about microstructural effects of different alloys in a macroscopic dimension. Samples taken from cast rolls and investigation is done in comparably small areas in relation to the total surface of a roll. Strip rolling is and surface quality of the strip is in strong relation to the barrel surface quality. Effects of alloy and microstructure can appear anywhere on the barrel surface. To get a better understanding and knowledge about alloying trials in relation to surface quality, we decided to install the last version of LRI (Lismar Roll Inspection). LRI is the latest technology of Eddy Current with a higher resolution compared to existing systems. Depending on matrix and free graphite and the balancing formation of carbide precipitations and carbide network the EC test can detect smallest differences. Different results of EC and UT surface wave inspection give the possibility to analysis and discussion. Rolls applied in the mill have given different results in respect of surface quality. A few examples of surface effects will be discussed and improvement strategies explained. Keywords: Grafitic HSS; Carbide enhancement; Segregation; Lismar roll inspection.
\end{abstract}

\section{INTRODUCTION}

Indefinite Chill cast iron (ICDP) rolls with different shell materials are cast for highest demands on wear resistance and surface quality in the finishing stands of hot rolling mills. Historical types of this alloy are reported back until the 1930ies [I] and since that time continuous improvement and modification took place. One of the last big steps was the development of so-called carbide-enhanced types, where the reinforcement of the microstructure was made by $\mathrm{Nb}$ - and/or $\mathrm{V}$-rich $\mathrm{MC}$ carbides. Still the microstructure of ICDP shell alloys consists of tempered martensite, cementite $\left(\mathrm{M}_{3} \mathrm{C}\right)$, graphite and $\mathrm{MC}$ carbides [2-5].

The wear resistance improvement of this type of alloy, in the recent years showed several approaches [5-9]. It was considered to develop graphite containing roll materials which consist of more wear resistant carbides than cementite. "Graphitic HSS" is the synonym for this new alloy type in the hot rolling business.
Eisenwerk Sulzau-Werfen (ESW) is one of the leading roll manufacturers of high-performance work rolls. The worldwide patent for the VIS grade [10] marked a breakthrough in the development of more wear resistant Indefinite-Chill work roll grades. The graphitic HSS at ESW dates back until the year $\mathbf{2 0 0 0}$ when the first type of grafitic HSS(VANIS) was delivered. Today the product range for surface-critical roll grades includes VIS, VANIC, VANIS and VANIMO and the most-suitable roll grade will be selected according to the situation and application of the customer

All developments of high-performing work roll grades were trialed in close cooperation with selected customers. Together these roll grades were successfully introduced and tested. The melting and casting procedure as well as the chemical composition and microstructure was continuously improved and "fine-tuned"

'Eisenwerk Sulzau-Werfen, R\&E Weinberger AG, Tenneck, Salzburg, Austria. E-mail: michael.brandner@esw.co.at 'LISMAR Engineering, Ouderkerk A/D, Amstel, Netherlands.

2176-I523 (C) 2020. Brandner et al. Published by ABM. This is an Open Access article distributed under the terms of the Creative Commons Attribution License, which permits unrestricted use, distribution, and reproduction in any medium, provided the original work is properly cited. 


\section{MATERIAL AND METHODS}

\section{I Metallurgy of Graphitic HSS Grades}

ESW rolls are produced by means of the horizontal spincasting process, see Figure I. The first step is the spincasting itself $(\mathrm{I})$ where the shell material is cast at high centrifugal forces. The solidified shell material together with the spincasting mold is transferred to the bottom mold and closed by the top neck parts (2). the final stepis the core filling (usually nodular cast iron) ensuring good bonding zone between shell and core (3).

VANIMO the Graphitic HSS grade is based on conventional ICDP grades but are strongly customized. This means, the chemical analysis and the microstructure originate from the orifginal ICDP alloy type. Table I shows the range of the chemical composition for conventional ICDP materials according to $[2,3]$. The $C$ content is around $3 w t .-\%$ and the Si can reach values between 0.7 and I. 3 wt.- $\%$. The $\mathrm{Mn}$ content is at low levels of about $0.5 \mathrm{wt} . \mathrm{\%}$. The fraction of $\mathrm{Ni}$ can reach levels of up to 3 times the amount of $\mathrm{Cr}$ in the alloy while Mo is between 0.2 and 0.6 wt.-\%.

The microstructure of conventional IC shell material consists of ledeburitic carbides ( $\mathrm{Fe}, \mathrm{Cr})_{3} \mathrm{C}$ in a range of $35-40 \%$ area fraction, tempered martensite and (chainlike) graphite. The orientation of the graphite follows the solidification direction [2] in a conventional ICDP roll grade.

In the last finishing stands of hot strip mills the challenges for work rolls can be summarized as follows [12]: The rolls must have a low friction coefficient and a low sticking tendency, a good resistance against cracks due to mechanical overload in the mill and an excellent surface quality.

High-Speed Steel (HSS) work rolls are widely used in the early finishing stands of hot strip mills. These alloy types are the in terms of wear resistancwe of cast work rolls [2]. The chemical analysis is based on carbide forming elements in high amounts, see Table 2. V, Mo, Cr, and W contents around 5 wt.-\% or even more are typical for high-performing HSS work rolls.
In the last recent years, the wish of roll users has been the development of roll grades which combine maximum wear resistance with the good surface and operating condition of ICDP rolls [5-9].

ESW's product portfolio reaches from standard grade (VISG) to Carbide-Enhanced ICDP (VIS) over a modified ICDP grade (VANIC) to graphitic HSS (VANIS and VANIMO), see Figure 2.

The VANIC marks an important intermediate step when composing the very high alloyed graphitic HSS grades VANIS and VANIMO. The chemical composition of graphitic HSS is shown in Table 3. The carbon equivalent (CE) can reach values higher than 4 wt.- $\%$. The amount of carbide

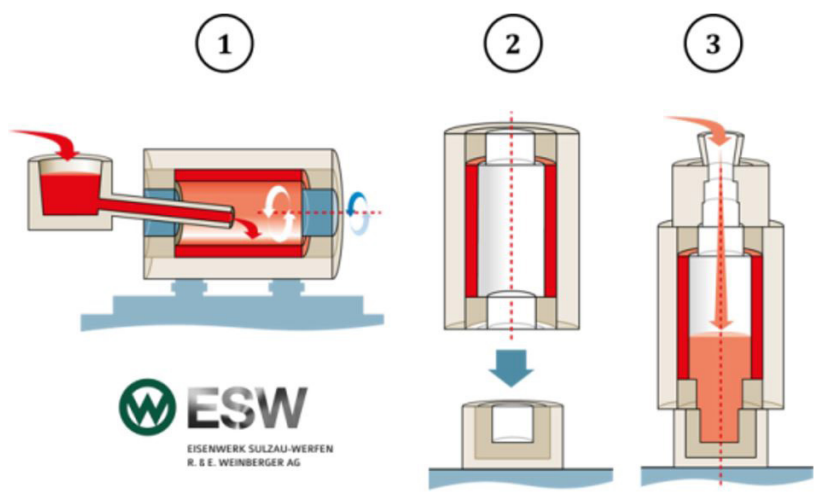

Figure I. Production route of ESW's horizontal spincasting process for work rolls [II]. I: Spincasting of the shell material, 2: Mounting of the molds, 3: Casting of the core material.

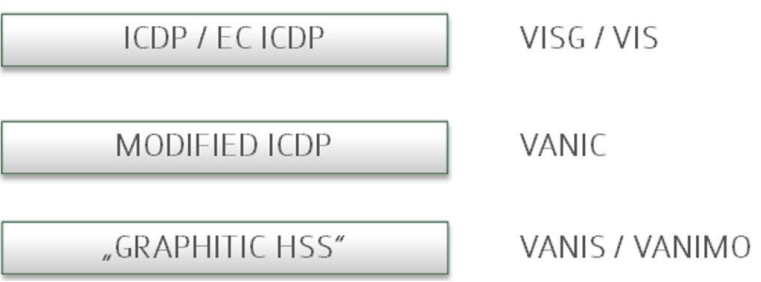

Figure 2. ESW's product portfolio for the last finishing stands of hot rolling mills.

Table I. Typical chemical composition of conventional ICDP alloys in wt.-\% according to [2,3]

\begin{tabular}{ccccccc}
\hline & C [\%] & Si [\%] & Mn [\%] & Ni [\%] & Cr [\%] & Mo [\%] \\
\hline $\operatorname{Min}$ & 2.8 & 0.7 & 0.3 & 3.5 & 1.5 & 0.2 \\
$\operatorname{Max}$ & 3.5 & 1.3 & 0.8 & 5.0 & 2.0 & 0.6 \\
\hline
\end{tabular}

Table 2. Typical chemical composition of HSS alloys in wt.-\% according to [2]

\begin{tabular}{cccccccc}
\hline & C [\%] & Mn [\%] & Ni [\%] & Cr [\%] & Mo [\%] & W [\%] & V [\%] \\
\hline Min & 1.4 & 0.3 & 0.3 & 4.0 & 2.0 & 0.0 & 4.0 \\
Max & 2.2 & 0.8 & 1.2 & 8.0 & 6.0 & 5.0 & 7.5 \\
\hline
\end{tabular}

Table 3. Ranges of the chemical composition for graphitic HSS grades such as VANIMO in wt.-\%

\begin{tabular}{ccccccccc}
\hline & CE [\%] & Mn [\%] & Ni [\%] & Cr [\%] & Mo [\%] & W [\%] & V [\%] & Nb [\%] \\
\hline $\operatorname{Min}$ & 2.8 & 0.5 & 4.0 & 1.0 & 0.5 & 0.0 & 1.0 & 0.5 \\
$\operatorname{Max}$ & 4.2 & 1.5 & 6.0 & 3.0 & 4.0 & 3.0 & 4.0 & 2.0 \\
\hline
\end{tabular}


forming elements $\mathrm{Cr}, \mathrm{Mo}, \mathrm{W}, \mathrm{V}$ and $\mathrm{Nb}$ are ranging between the chemical compositions of conventional ICDP (Table I) and HSS (Table 2).

The graphitic HSS roll grade has a basis microstructure, like in case of ICDP roll grades, of cementite and graphite embedded in tempered martensite. In between very hard carbides such as $M C$ and $M_{2} C / M_{6} C$ types are present in the microstructure. An example of VANIMO microstructure is shown in Figure 3.

\subsection{Performance of VANIMO}

Rolled tons or rolled kilometers per $\mathrm{mm}$ shell material are wear indicators for work rolls. Additional grind-offs which are related to incidents in the mill have to be excluded - otherwise the performance figure is misleading

Figure 4: Wear performance of VIS, VANIC and graphitic HSS (VANIS/VANIMO) in the last 3 stands of a 7 stand mill are in comparison. In this case, the pure wear on the work roll is displayed (not the stock removal). Stand by stand the performance of the roll grades is displayed.

The largest benefits were achieved in stand $\mathrm{F} 4$, where the performance of VANIC was $+26 \%$ in comparison to VIS. The graphitic HSS grades reached an increase of $+160 \%$. This trend is also visible for VANIC and VANIMO in stand F5 (VANIC $+20 \%$, VANIMO + 154\%), followed by stand F6 (VANIC + 18\%, VANIMO + 47\%).

In summary, VANIC reaches $+12 \%$ in comparison to VIS while the graphitic HSS grades achieve $+98 \%$ in pure wear. The wear performance of the work roll is not only influenced by the work roll grade but also by the rolling conditions in the mill, abviously shown by the values.

The extreme values of the graphitic HSS grades to the carbide enhanced VIS and the modified work roll grade VANIC is clearly visible and contributes to the reduction of the total cost of ownership (TCO) for the roll user.

\subsection{Surface Quality of VANIMO}

Graphitic work roll grades are used for mainly for high abrasive materials up to surface critical products in hot rolling mills. This means that the rolls are used in the last stands of hot strip mills and the surface of the barrel consequently is imprinted on the strip surface. Barrel surface influences the quality of the strip surface which may cause quality issues on the strip in case of insufficient barrel surface. Hereinafter some possible barrel surface quality problems are presented. Some examples and reasons of the defect types as well as the remedies will be discussed.

\subsection{Gravity Segregation}

The process is related to high centrifugal forces in the mould during spinning. During solidification of the liquid shell material so-called "gravity-segregation-effects" can occur within the shell material. Wear resistant phases such

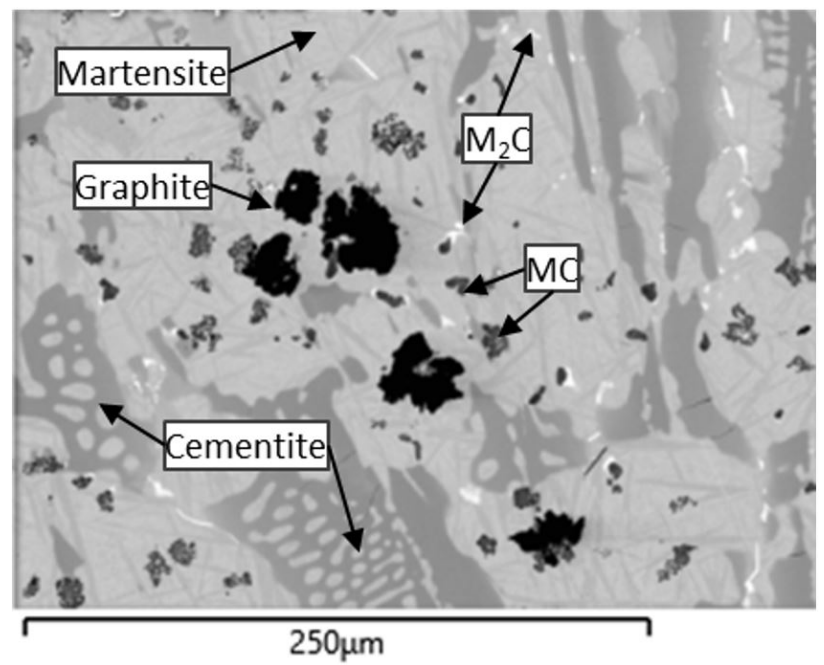

Figure 3. Microstructure of VANIMO with $M C, M_{2} C$ and $M_{3} C$ carbides as well as graphite embedded in tempered martensite.

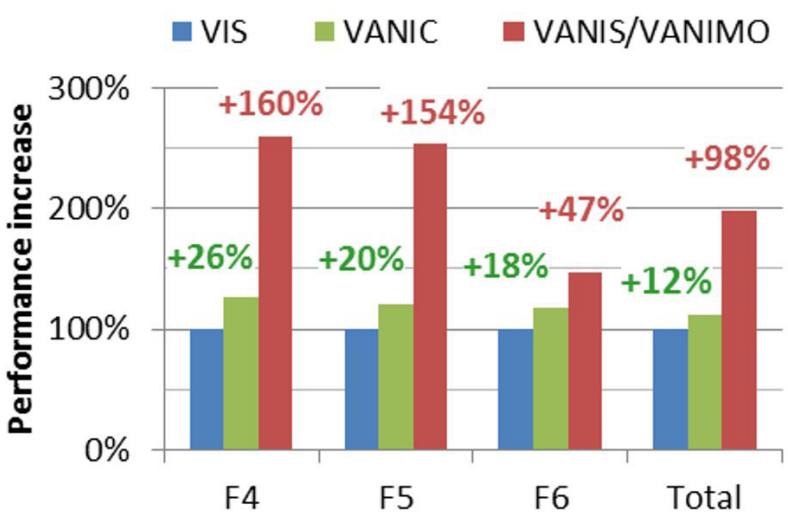

Figure 4. Wear performance of VIS, VANIC and graphitic HSS (VANIS/VANIMO) in the last 3 stands of a 7 stand mill.

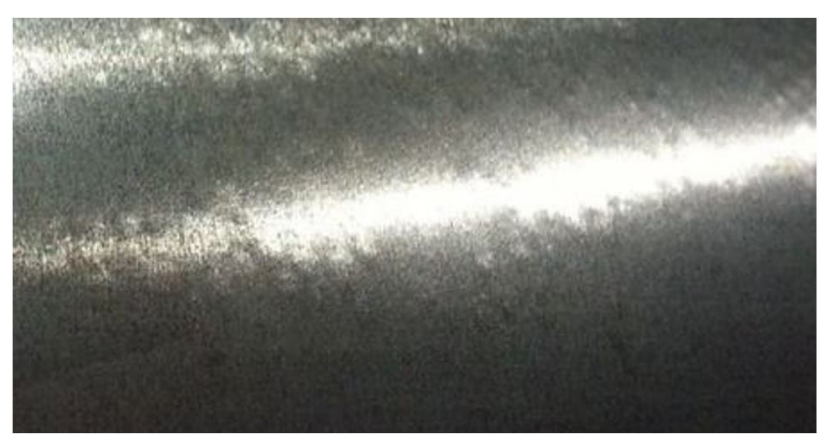

Figure 5. Possible appearance of segregated carbides on the barrel surface.

as carbides can agglomerate and segregate. Applied in the mill the wear on the barrel surface develops irregularly and may look as shown in Figure 5.

If their density is too different all phases follow Stoke's law [I3] and may segregate. This effect is even stronger if the process is overlaid by mechanical oscillations or vibrations.

The surface shown in Figure 6 investigation clearly shows agglomerations of small MC carbides, shown in 
white. MC carbides are the hardest carbide types $[14,15]$ and therefore are highly wear resistant. The distribution of this carbide type is most important and has to be very homogenuos, otherwise the wear on the barrel surface develops irregularly

The remedies for gravity segregations are:

Completely avoid oscillations and vibrations during the spincasting process;

Ensure densities of the phases are similar by adjustment of chemical composition;

To keep the solidification gap as narrow as possible, adjust the chemical composition;

Avoid nuclei (oxides, nitrides) which promote precipitation of carbides at high temperatures.

\subsection{Insufficient Dissolving of Ferroalloys}

high amounts of alloying elements have to be added in form of ferroalloys when producing graphitic work roll materials. Some ferroalloys have very high solidus temperatures [16] and is difficult to get a proper dissolving in the melt. In special cases, ferroalloy needs diffusion processes during melting to dissolve. This can lead to additional challenges.

A full dissolution and homogeneous distribution of the ferroalloys in the melt is essential. Figure 7 shows an insufficiently dissolved ferroalloy in barrel surface with particles which lead to imprints in the rolled material. these defects may be found during roll testing, by Eddy Current (EC) or UT surface wave testing. Also liquid penetration testing (PT) or magnetic particle testing (MT) clearly reveal such defects. They appear as small cracks or porosities when they reach the barrel surface.

A metallographic sample taken from including such a defect and etched with 5-\% Nital, the microstructure looks as shown in Figure 8. Carbides appear white and the matrix as well as the graphite particles are black. The normal microstructure shows typical ledeburitic carbides with an area fraction of about $35 \%$. The insufficiently dissolved ferroalloy has a much higher carbide fraction and much finer structure.

Figure 9 shows the depth profile of such defect. The round graphite particles are shown in black, the matrix and cementite in grey. The white structure is showing the insufficiently dissolved ferroalloy in a leave like structure. The particle depth is approximately $\mathrm{I} \mathrm{mm}$ from the barrel surface. The dissolving

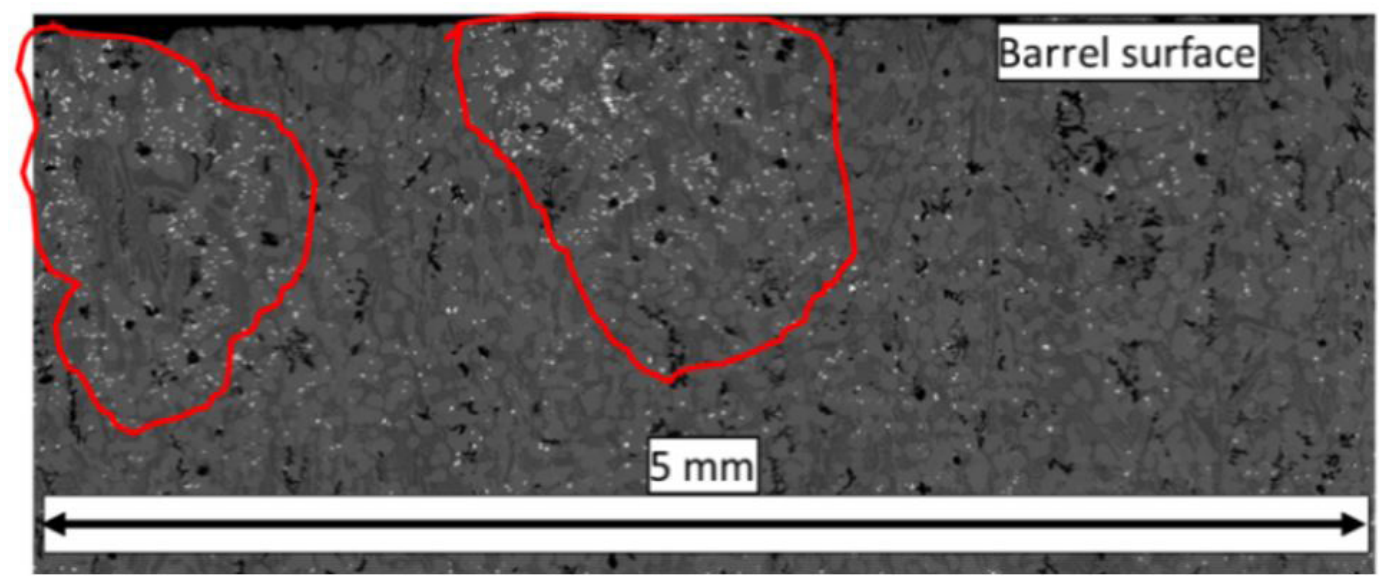

Figure 6. SEM-BSE investigations of segregated carbides in a graphitic work roll grade.

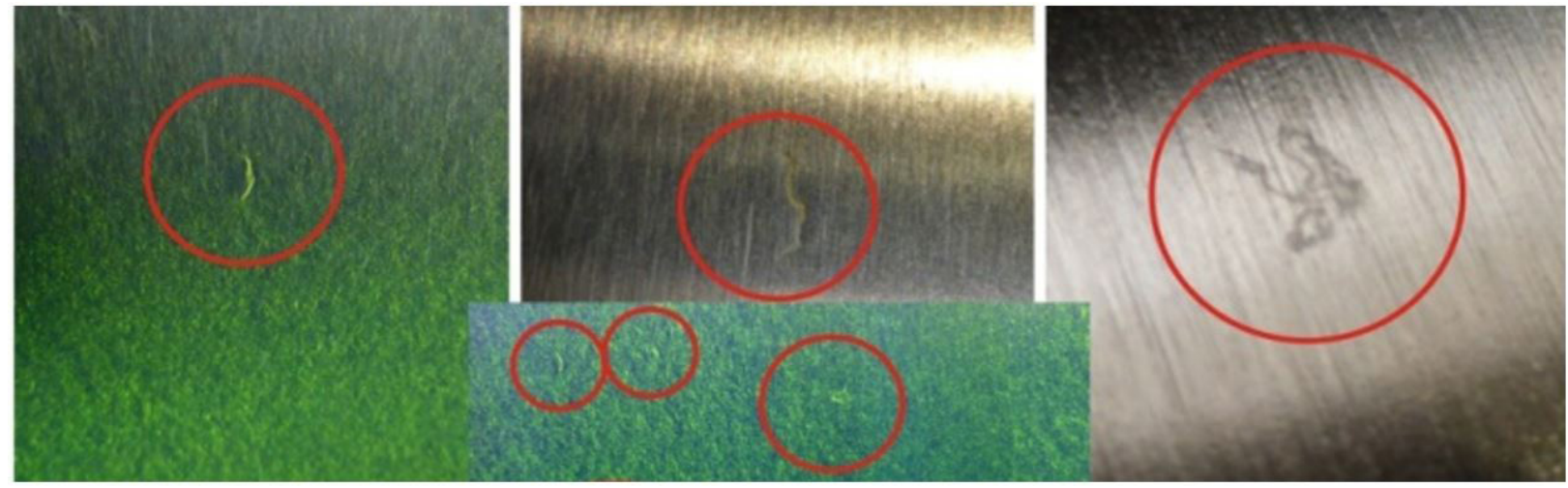

Figure 7. Typical appearance of insufficiently dissolved ferroalloys. 


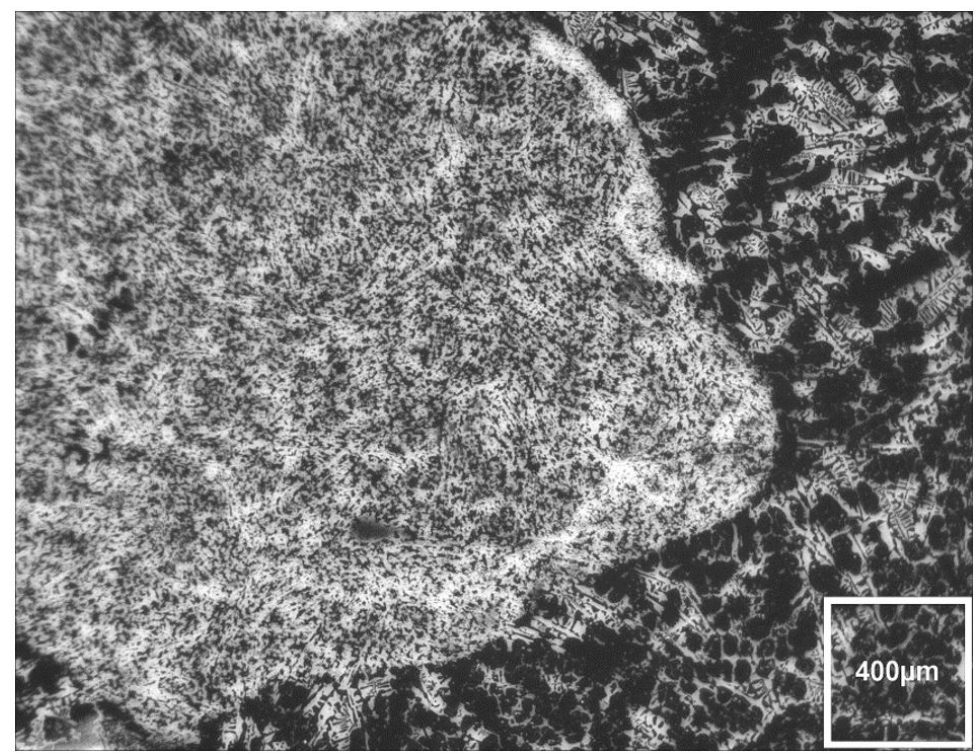

Figure 8. Light-optical image of an insufficiently dissolved ferroalloy.

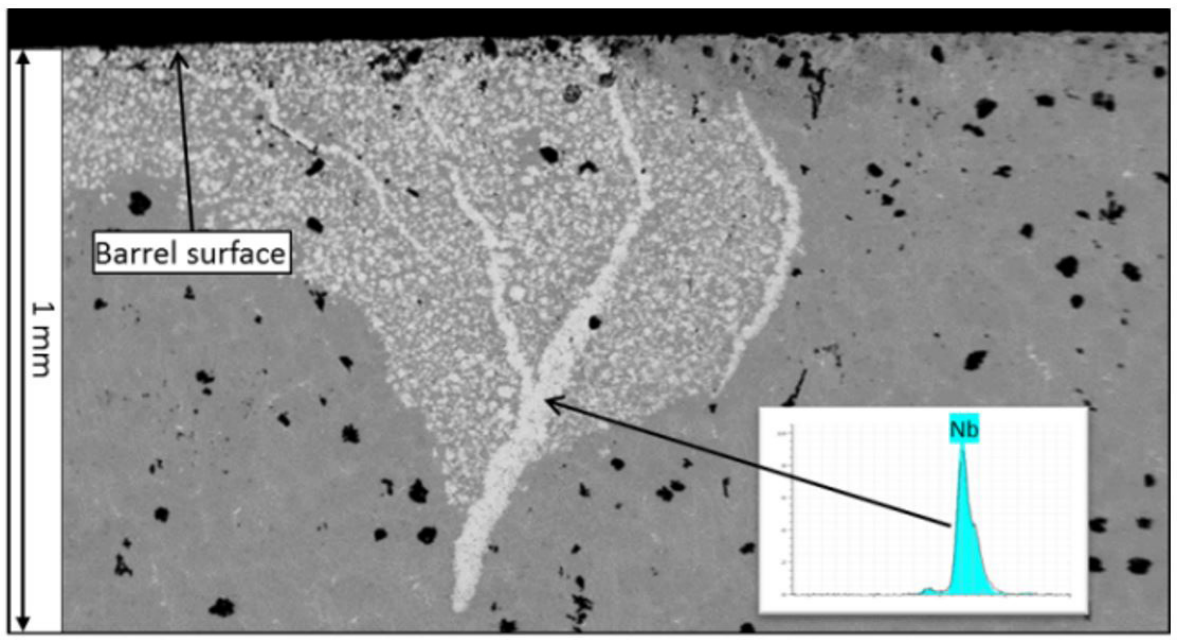

Figure 9. SEM-BSE image of the depth profile of insufficiently dissolved FeNb.

process was just in progress when the metal solidified. The EDX scan confirmed the particle contains high fraction of $\mathrm{Nb}$ which means that the dissolving process of FeNb was insufficient.

The remedies for insufficiently dissolved ferroalloys are:

Overheating with an appropriate temperature of the melt;

Ensure long enough time for diffusion process;

Reduce the grain size of the ferroalloy (instead of $<5 \mathrm{~mm}$, go for $<2 \mathrm{~mm}$ ).

\subsection{Degenerated Carbides}

For high-performance work roll grades such as VANIMO, not only the morphology of carbides but also the correct amount and type is essential. Figure 10 shows an example, where "degenerated" carbides are present. This means carbides with unusual morphology - lead to some surface pattern on the work roll. The pattern in Figure 10 somehow look like water spots but with metallurgical background.

Figure I I gives a detailed view on such "water spot line". It reveals its macroscopically clear line appearance. Performing a large area EDX mapping shown in Figure 12 tells that the amount of $\mathrm{V}$ is not homogeneously distributed. $\mathrm{V}$ is agglomerated in one line which is the same as the macroscopically visible one.

This also can happen with Nb (not shown here). $\mathrm{MC}$ carbides based on $\mathrm{V}$ and $\mathrm{Nb}$ are arranged in lines which cause the pattern on the work roll surface.

Looking at the morphology of the MC carbides clear deviations between two MC carbides types are detectable. The first type is shown in Figure 13, where the white MC carbides appear in a clear cubic structure.

The second type of MC carbides is shown in Figure 14. 


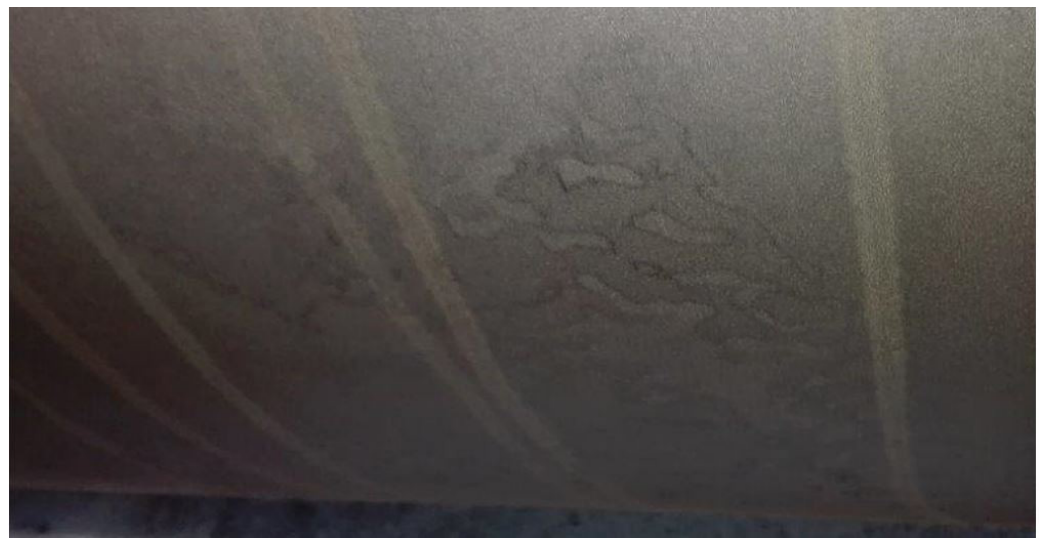

Figure 10. Possible appearance of "degenerated" carbides on the barrel surface.

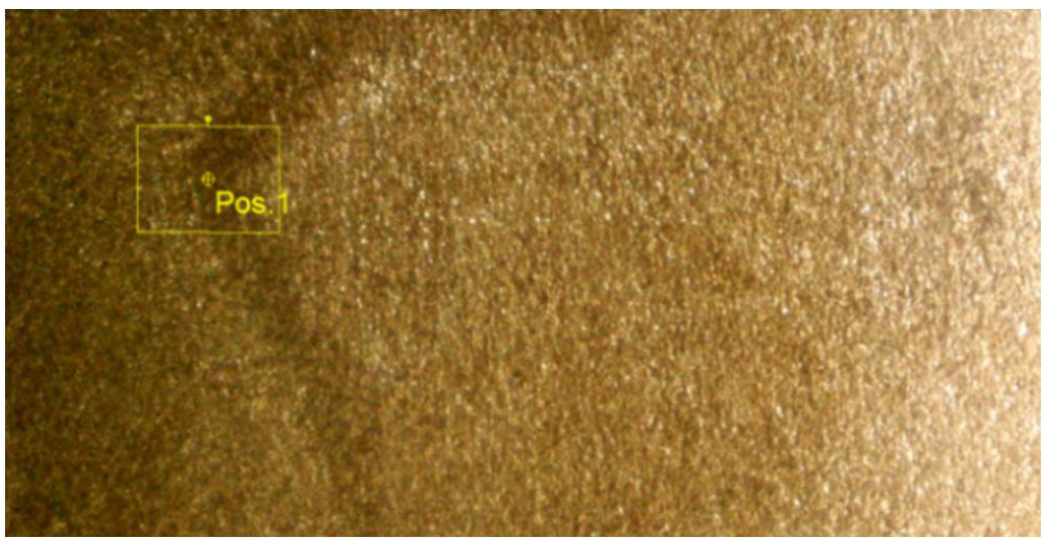

Figure I I. Detail of degenerated carbides.

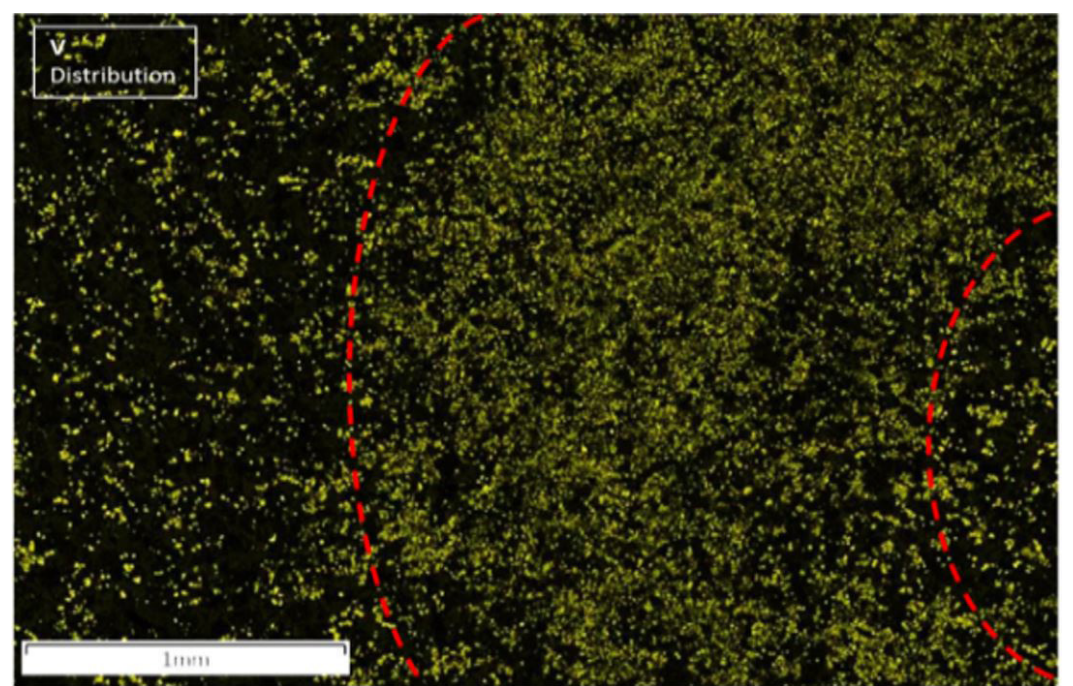

Figure 12. SEM large area mapping of $\vee$ distribution.

The MC carbides (white in the picture) have a more irregular shape. They are much smaller than the ones in Figure 13. In addition they tend to agglomerate and form lines which result in "water spot lines" on the barrel surface.

this defect requires intensive investigations including SEM/EDX investigations and thermodynamic calculations to find the root cause. Carbides change themselves or completely change their morphology influenced by the chemical composition [17-20]. The remedies are related to the chemical analysis for this defect and strongly depend on the root cause of the melt and the degenerated carbides themselves. It is essential to look at obvious alloying elements such as $\mathrm{V}, \mathrm{Nb}, \mathrm{Mo}$ and $\mathrm{Si}[17]$ but even among others such as small fractions of $\mathrm{B}$ [18], Ti [19] or N [20]. 


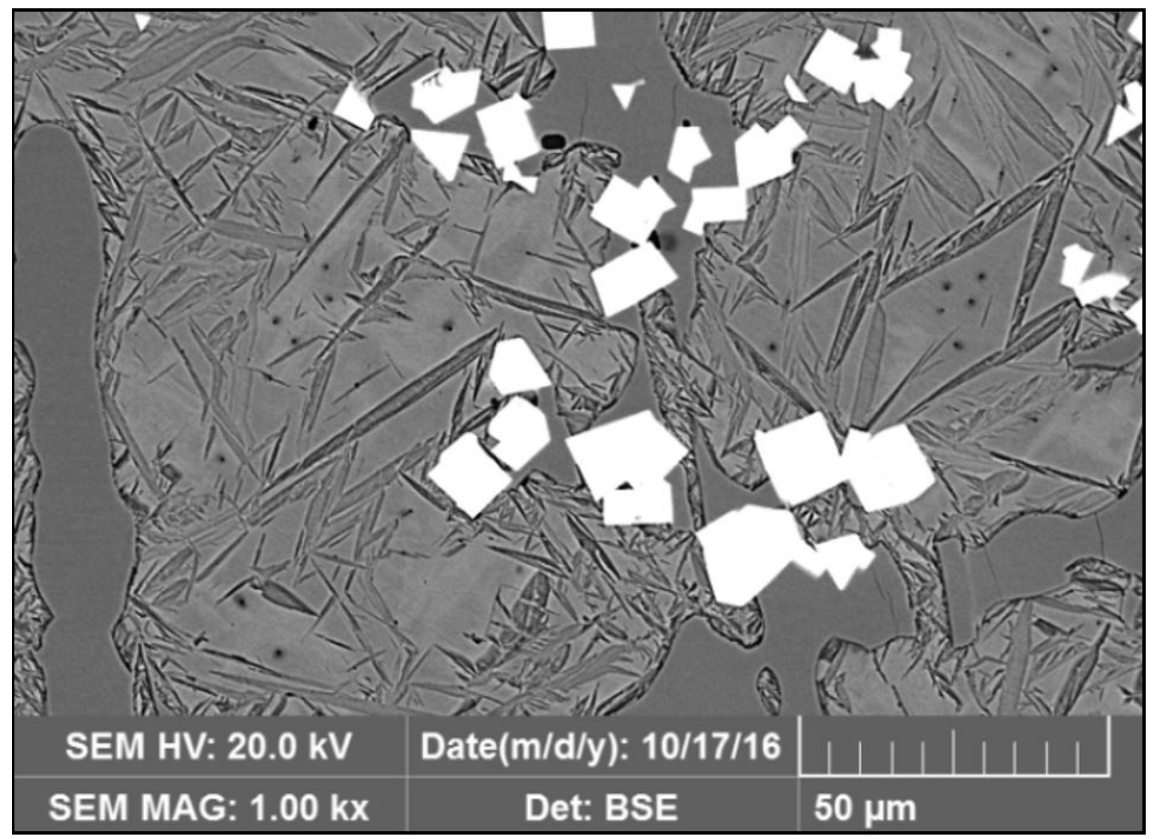

Figure 13. Cubic morphology of MC carbides (white) in a graphitic work roll grade.

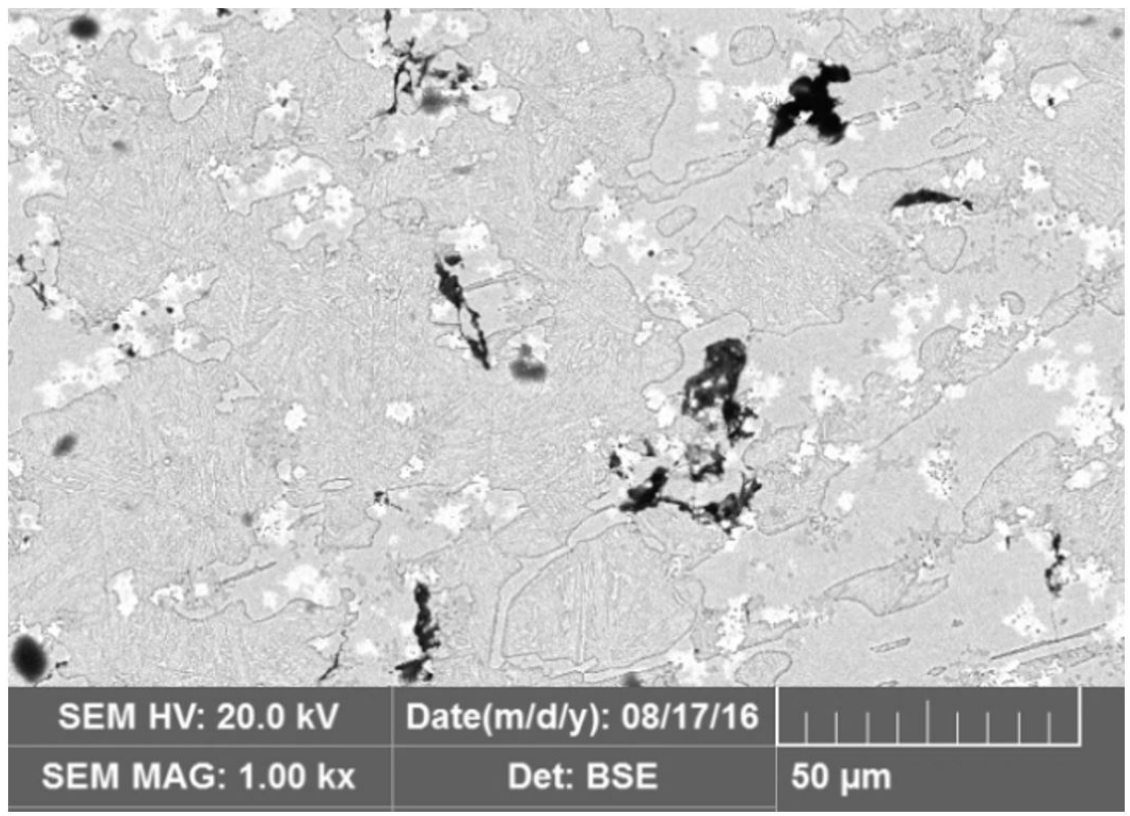

Figure 14. SEM-BSE image of degenerated MC carbides (white).

\section{7 "Cloud Pattern"}

Up to now the defects on the barrel surface were clearly related to microstructural and therefore metallurgical aspects in roll manufacturing. A very critical phenomenon is the formation of a "cloud-pattern" on the surface of ICDP roll grades. Figure 15 shows the appearance of this defect on the barrel surface.

It can be described as very small variations in the surface of the work roll and can be very hard to identify. Anyhow in some mills and some applications the pattern is transferred to the strip and detected by the automatic surface inspection systems.

ESW's experience with this defect is in full agreement with the investigations of [2I], where a study about this effect for various ICDP roll grades was performed.

This means that:

The phenomenon may appear intermittently;

No relation between specific parameters or periods was found; 


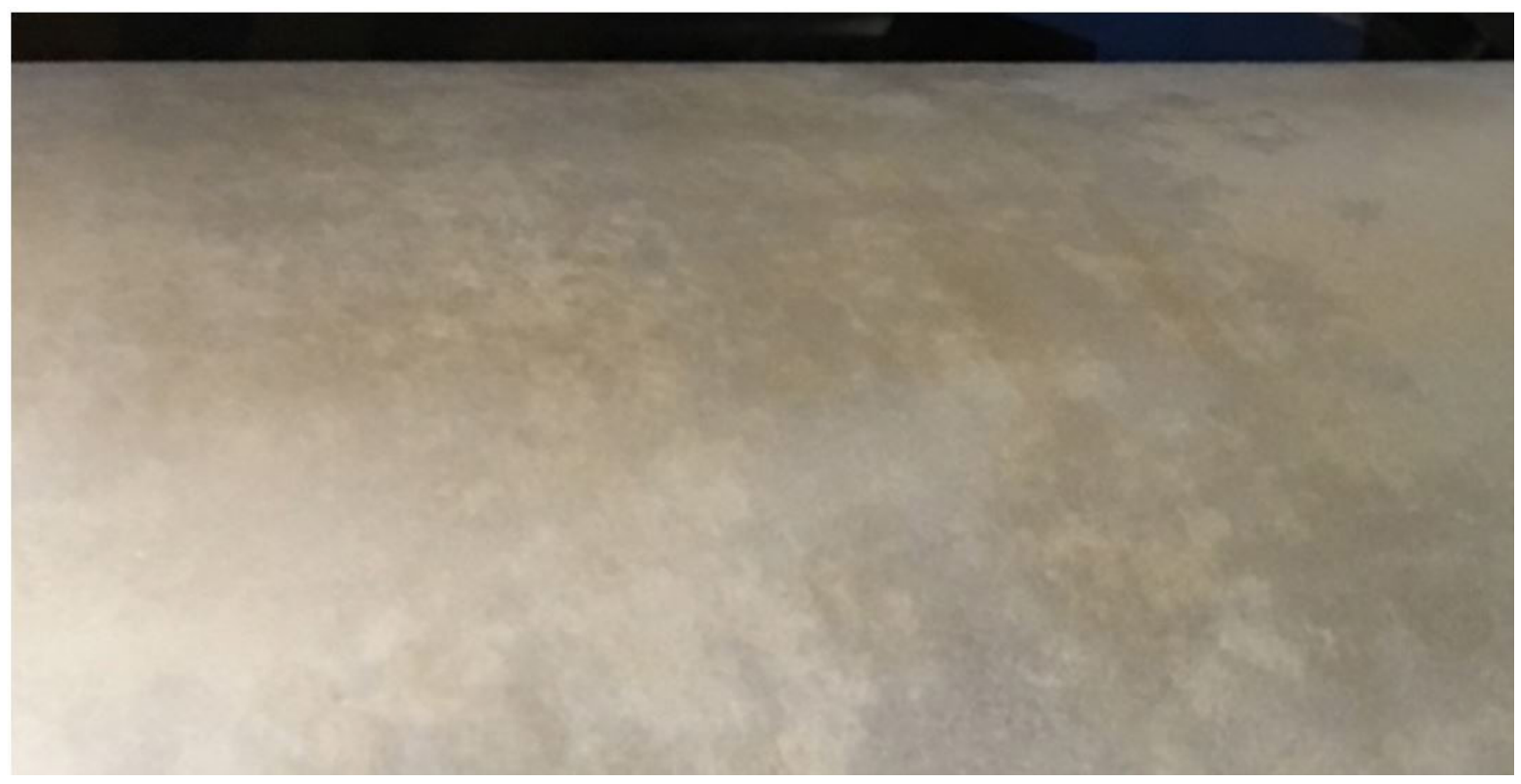

Figure I5. Barrel surface with "cloud-pattern".

It is not related to the mill stands and types (carbon/stainless steel, steckel/continuous mills).

There is no relation to specific ICDP roll grades but it is more likely that highly wear resistant grades (such as graphitic HSS) may form this pattern more easily.

From the position of a roll producer, the cloud-pattern is not related to variations in the surface profile, surface cracking, chemical segregations, bulk or microhardness. Additionally the microstructure does not correlate to this effect [2I]

Based on these results, it can be assumed that the rolling process with all parameters (temperatures, forces, cooling, grinding procedure,...) plays an important role in the formation of the cloud-pattern effect. Therefore it is essential to have close cooperation between the roll manufacturers and the rolling mills to determine the root causes of this phenomenon to finally prevent it.

\subsection{Installation of LISMAR LRI}

To get a better understanding of all those phenomena of surface patterns, ESW decided to make an investment in the future. So far ESW had investigated all the differently described cases on different samples taken from a roll. Therefore it was essential to have a roll with known defects where samples could be extracted. This was always in a late stage, mostly final grinding. ESW has been searching for a possibility to work pro-active. Means, to make changes in production and test the result directly in the company on large scale dimensions and not on very small metallographic sample. Long time ago Lismar already had supplied the system Lismar Datames for roll testing, which was installed at ESW. The testing system consisted of several UT probes such as $2 \mathrm{MHz}$ straight beam, $4 \mathrm{MHz}$ TR and a surface wave probe.
With none of them a microstructural property could be detected. The new development of the EC probe from Lismar was the trigger to decide to make such an investment. The key improvements of this new eddy current inspection technique are:

- Higher sensitivity for smaller cracks and detection of structure changes due to the EC reflection setup [22];

- Higher resolution and defect information due to use of small coils and digital signal processing;

- Faster scanning due to a wide array of coils within the probehead;

- Fully digitial and fast processing due to use of FPGA technology.

For ESW the improvement of a far better resolution and separation between crack and microstructural indications gave the breakthrough to invest. The improvements are a promise to detect described cases and have a quicker respons to support the investigations.

The installation of this new LRI system took place in August 2018. From that time on all roll scans are performed with eddy current and ultrasound inspection technology.

The new LRI configuration is very compact. A controlpanel with screen and integrated PC as shown in Figure 16 is installed on the grinding machine. The second part is the so called iPPS (intelligent Probe Positioning System). This part controlls the probehead very accurate towards the roll surface to perform the automation. See Figure 17

Figure 18 is showing the actual probe head configuration of this ESW automatic roll inspection system. There are the 3 described UT probes, same as in the 


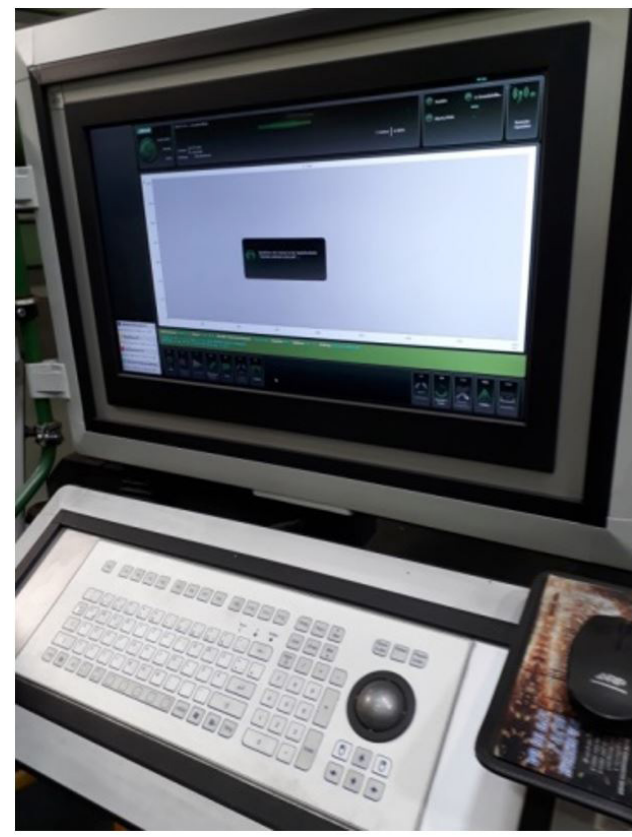

Figure I6. LRI Control Panel (Screen and PC).

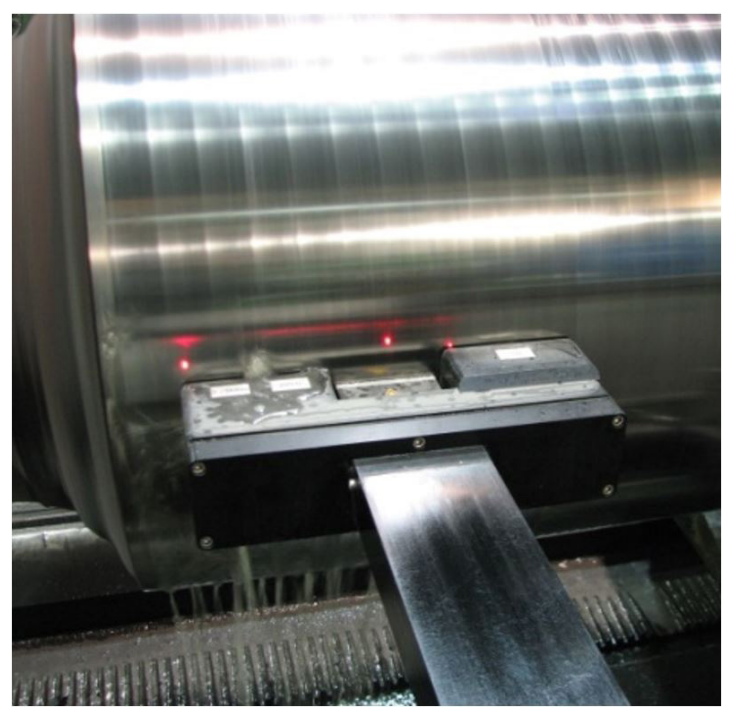

Figure I7. LRI intelligent Probe Positioning System. former configuration and the new eddy current sensor in the center of the probe head.

\section{RESULTS AND DISCUSSION}

\section{I Chrome Steel Roll Examination}

For this investigation we took a special alloy of chrome cast steel. To see if the alloy is uniform we ground the roll in $5 \mathrm{~mm}$ steps down followed at each step by a scan on the LRI System.The following Figures 19-23 show the different stages of the ground roll.

In the different figures we can see, that some microstructural indications appear and disappear. The metallurgical background is a small variation in the carbide content of the ledeburitic network carbide.

\subsection{HSS Roll Examination}

A HSS roll was in service at a customer, when some indications on the test system appeared which could be highlighted by manual inspection.

Figure 24 shows the detection of a surface pattern during service in the rolling mill. The roll was one of the first rolls tested on the new LRI System at ESW.

The post processing with changed parameters proved that some indications were already present during the tests at ESW. At that time the knowledge about different indications was not enough to decide not to deliver the roll to the customer. This investigation has lead to an adjustment of the evaluation threshold for the different channels.

Figure 25 shows the detection in the circled area containing signals from the 2 directions of the surface wave probe and the EC microstructural indication.

\subsection{Grafitic HSS Roll Examination}

The EC microstructure of a HSS roll gave some indication as shown in Figure 26 and marked with the black circle.

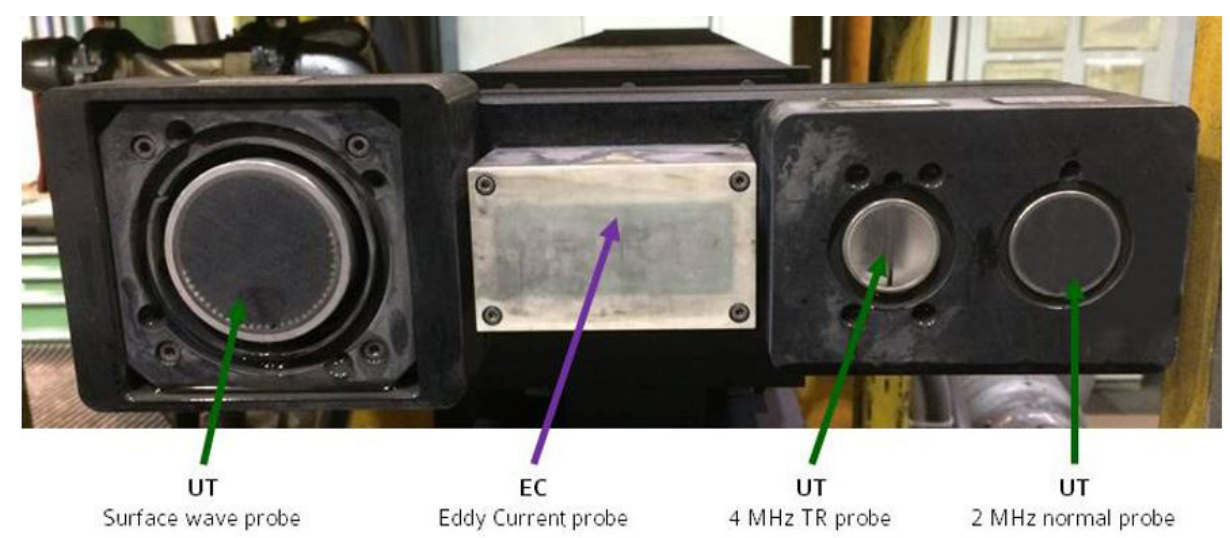

Figure 18. Probe head configuration. 


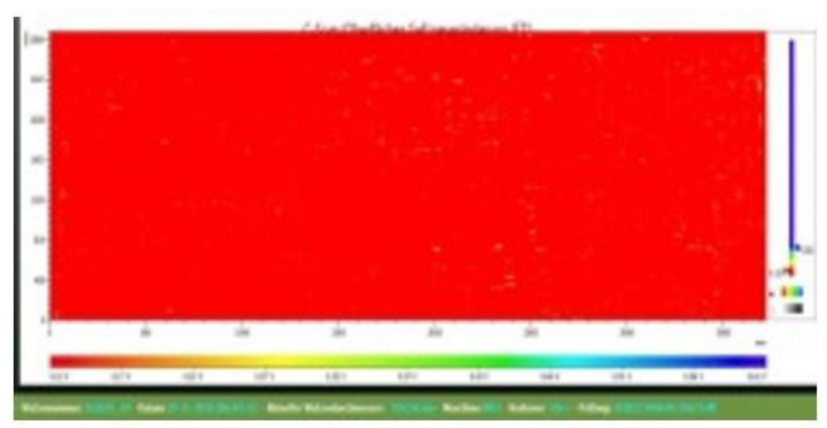

Figure 19. C-scan at $\varnothing 935 \mathrm{~mm}$.

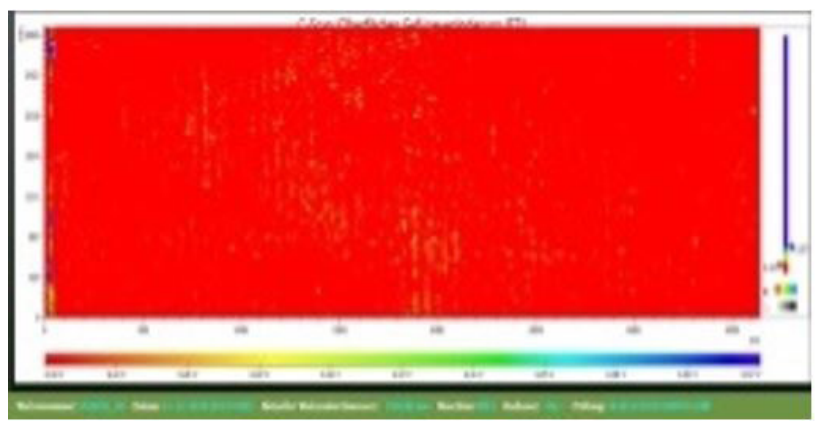

Figure 20. C-scan at $\varnothing 925 \mathrm{~mm}$.

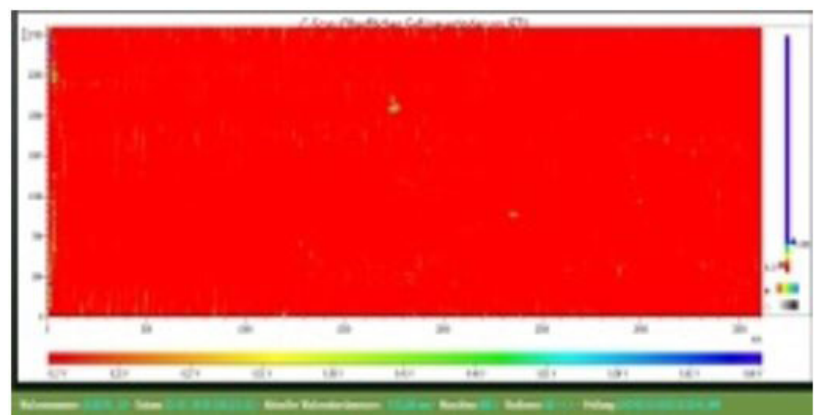

Figure 21 . C-scan at $\varnothing 915 \mathrm{~mm}$.

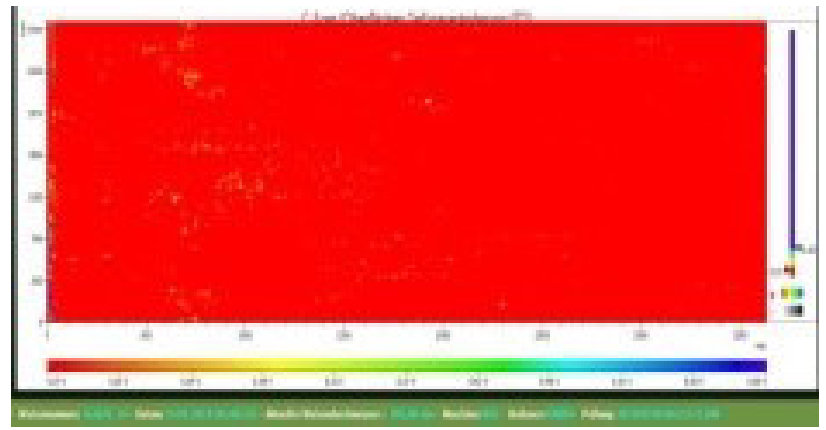

Figure 22. C-scan at $\varnothing 905 \mathrm{~mm}$.

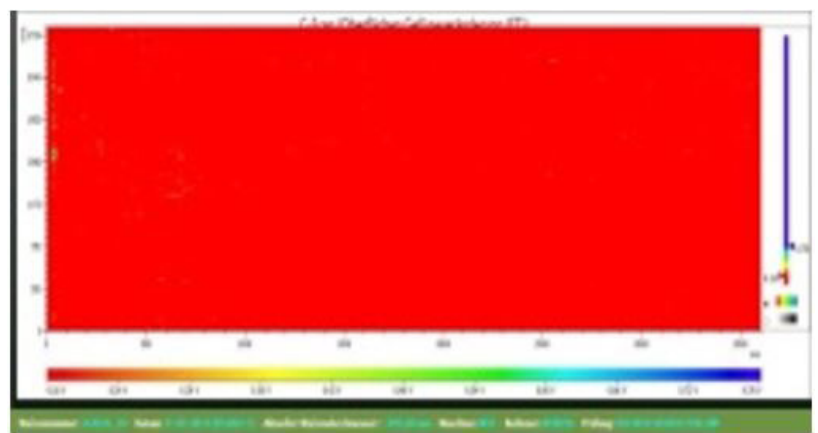

Figure 23. C-scan at $\varnothing 895 \mathrm{~mm}$.

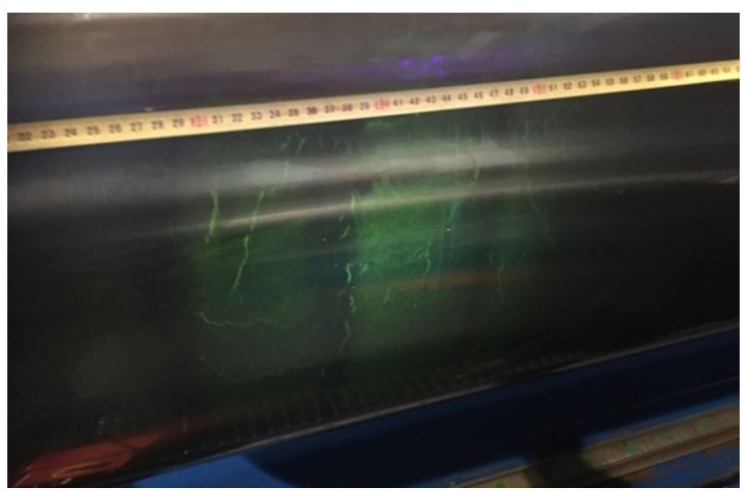

Figure 24. Fluorescent magnetic particle test under UV light.

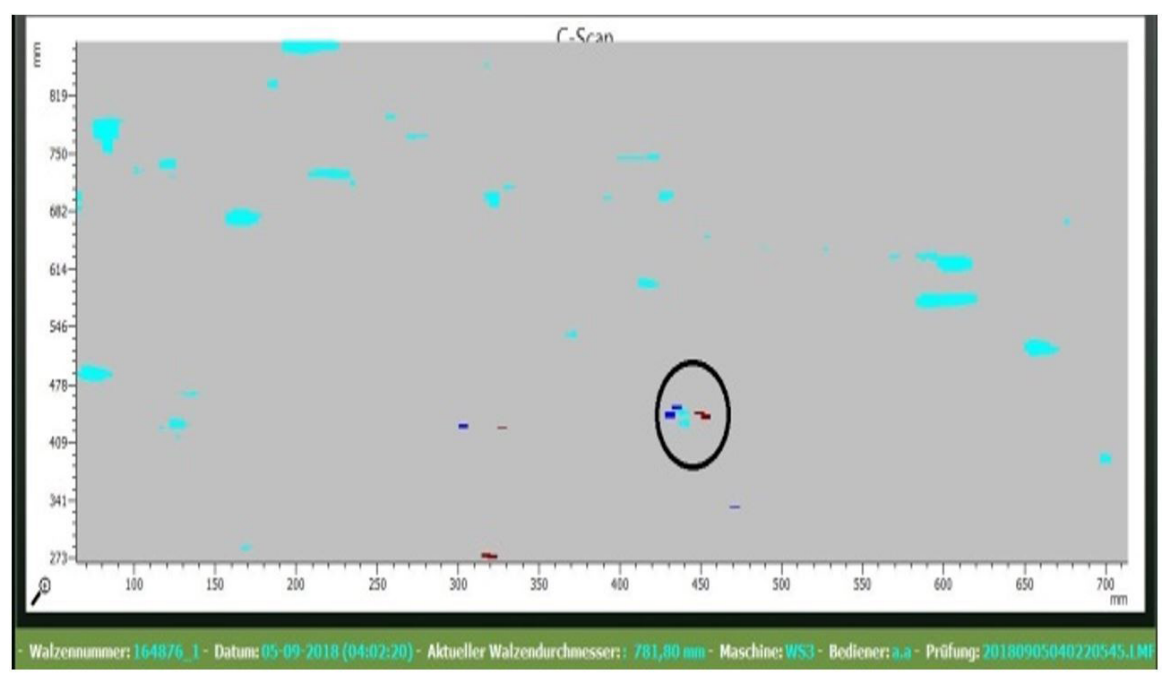

Figure 25. Indication of dected area on the roll. 


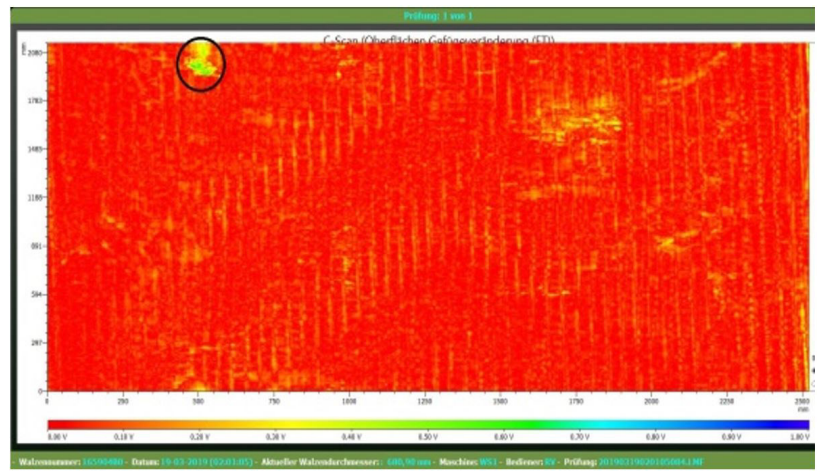

Figure 26. EC C-scan microstructure changes.

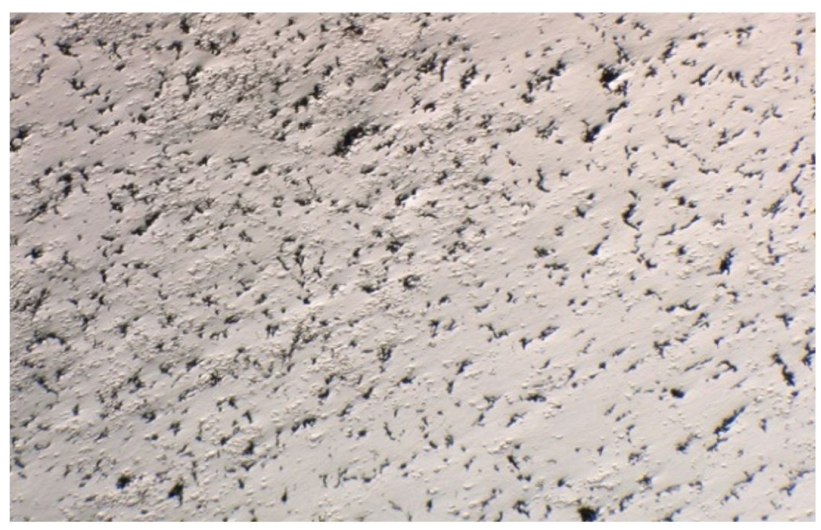

Figure 27. Left top, MC carbide agglomeration.

Then metallographic investigation took place. As can be seen in Figure 27, the metallographic investigation brought up the high density of MC carbides. This gives a high signal in the EC microstructure channel. In total the

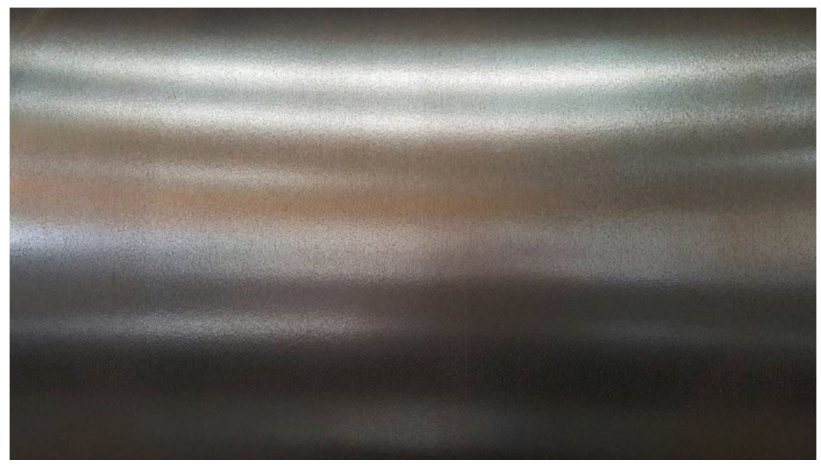

Figure 28. Smooth VANIMO barrel surface without irregularities after rolling a campaign with $\sim 4700$ tons.

MC precipitation was not uniform over the localized area in the barrel.

\section{CONCLUSION}

Graphitic HSS such as VANIMO are high-performing roll grades for the application in surface-critical stands in hot rolling mills. The wear performance of graphitic HSS grades VANIS/VANIMO is $+98 \%$ and therefore results in large benefits for the roll user.

The surface quality of ICDP as well as graphitic HSS grades is essential for a proper usability in the rolling mill. Possible surface defects were presented and the remedies were discussed. The new possibility to detect such surface discontinuities with EC test methods makes it possible to make tests inhouse and achive results in shorter time and less workload in the mill. Together with our customers we try to achieve a smooth barrel surface as shown in Figure 28.

\section{REFERENCES}

I Roll F. Handbuch der gießerei-technik. Berlin: Springer-Verlag; 1960. p. 32I-328.

2 Lee G. Rolls for the metalworking industries. Warrendale, USA: Iron \& Steel Society; 2002. p. 4I-47.

3 Göbel H. Neue Gußeisenwerkstoffe für Walzen. ihre Eigenschaften und Verwendungsmöglichkeiten. Stahl und Eisen. 1957;77:143-157.

4 Feistritzer B, Schröder KH, Windhager M, Ziehenberger KH. Indefinite chill: Upgrading an old HSM work roll grade. In: Proceedings of the 4Ist MWSP Conference; 1999 Oct 2I-24; Baltimore, USA. Warrendale, PA: Iron and Steel Society. p. 103-108

5 Paar AM, Brandner L, Elizondo T, TrickI C, Sommitsch C. Béal: from ICDP to (graphitized) HSS: sophisticated work roll grades for highest demands in rolling mills for flat products. In: Proceedings of the Rolling 2016 Conference; 2016 June 6-9. Graz, Österreich. Leoben, Austria: ASMET, Austrian Society for Metallurgy and Materials.; 2016.

6 Bravo SV, Yamamoto K, Miyahara H, Ogi K. Control of carbides and graphite in cast irons type alloy's microstructures for hot strip mills. Materials Science Forum. 2007;56I-565:1023-1026.

7 Hattori TN, Oda N. Meada: latest development of cast rolls for hot strip mill finishing trains and other rolling mills. Proceedings of the Rolls 5th Conference; 20I5Apr 22-24; Birmingham; Großbritannien. London: The Institute of Materials, Minerals and Mining.; 2015. 
Brandner et al.

8 Oda N, Fleiner P, Toshiyuki H. Latest developments of a new technology hss work roll for later stands (F4-F7) in hot strip mill finishing trains. In: Proceedings of the AISTech 2013 Conference and Expo. 2013 May 6-9; Pittsburgh; USA. Warrendale: AIST; 2013 . p. 1977-1984.

9 Zybill C, Goryany V, Neumann M, Buch J, Römschmied M. New graphitised hss materials for rolls in finishing stands. Stahl und Eisen. 2015;135(I0):61-64.

IO Feistritzer B, Schröder KH, Windhager M, Ziehenberger KH, inventors; Eisenwerk Sulzau-Werfen R, Weinberger AG, applicants. Casting material for indefinite rollers with a sleeve part and method for producing the same. WO 00/65। 18. 2000.

I I Paar A, Brandner M, Aigner M, Elizondo L, Trickl T. Anzeigen bei der Ultraschallprüfung von Verbund-IndefiniteWalzen und deren Ursachen. Giesserei Rundschau 2018;65(5):6-I 2.

I 2 Flament S, Walmag G, Lemaire M, Sinnaeve M. Development of a new grade for rear finishing stands based on modeling and evaluation of specific degradations. In: Proceedings of the AISTech 2017 Conference and Exposition; 2017 May 8-I I; Nashville, USA. Warrendale: AIST; 20I 7. p. 2667-2676.

I 3 Nylén T. Niobium in cast iron. In: Proceedings of the International Symposium Niobium; 200 I Dec 2-5; Orlando, USA. Bridgeville, PA : Niobium 200I Ltd., C2002.; 2001.

I4 Theisen W. Hartphasen. In: Berns HH, org. Hartlegierungen und Hartverbundstoffe. Berlin: Springer-Verlag; 1998. p. 28

15 Girschowitsch N. Kristallisation und Eigenschaften von Gußeisen in Gußstücken. Moskau: Verlag Maschinostroenie; 1996. 562 p.

16 ASM International. ASM handbook Vol. 3 - Alloy Phase Diagrams. Ohio: AST International; 1992.

I7 Pavlina E, van Tyne C, Speer J. Effects of combined silicon and molybdenum alloying on the size and evolution of microalloy precipitates in HSLA steels containing niobium and titanium. Materials Characterization. 2015; I02:35-46.

18 Cöl M, Koc F, Öktem H, Kir D. The role of boron content in high alloy white cast iron (Ni-Hard 4) on microstructure, mechanical properties and wear resistance. Wear. 2016;348-349:158-165.

19 Cen Q, Jiang Z, Fu H. Effect of Ti addition on the microstructure and properties of a high speed steel roll. Materials Testing. 2013;55(II-I2):87I-876.

20 Ciesla M, Ducki K. Effect of increased nitrogen content on the structrue and properties of tool steels. Journal of Achievements in Materials and Manufacturing Engineering. 2008;29(I): I5-22.

2I Jonck J, Moema J, Jooste J, van Tonder P. Investigation of the 'tiger skin' defect on indefinite chill rolls. Journal of the Southern African Institute of Mining and Metallurgy. 20 I6; I 16:907-91 3.

22 van Kollenburg R, van den Elzen SM. Practical results of the next generation eddy current technology for roll inspection. In: Proceedings of the AISTech; 2016; Pittsburgh, USA. Warrendale: AIST; 2016.

Receiverd: 14 Jan. 2020

Accepted: 3 I Jan. 2020 